\title{
Observation of iron diffusion in the near-surface region of magnetite at $470 \mathrm{~K}$
}

\author{
Steffen Tober $\odot,{ }^{1,2}$ Marcus Creutzburg $\odot,,^{1,2}$ Björn Arndt $\odot,{ }^{1,2}$ Konstantin Krausert $\odot,{ }^{1,2}$ Stefan Mattauch $\odot,{ }^{3}$ \\ Alexandros Koutsioubas $\odot,{ }^{3}$ Sabine Pütter $\odot,{ }^{3}$ Amir Syed Mohd $\odot,{ }^{3}$ Lukas Volgger, ${ }^{4}$ Herbert Hutter, ${ }^{4}$ Heshmat Noei, \\ Vedran Vonk $\odot,{ }^{1}$ Dieter Lott $\odot,^{5}$ and Andreas Stierle ${ }^{1,2, *}$ \\ ${ }^{1}$ DESY NanoLab, Deutsches Elektronen-Synchrotron (DESY), D-22607 Hamburg, Germany \\ ${ }^{2}$ Physics Department, University of Hamburg, D-20355 Hamburg, Germany \\ ${ }^{3}$ Jülich Centre for Neutron Science (JCNS) at the Heinz Maier-Leibnitz Zentrum (MLZ), \\ Forschungszentrum Jülich GmbH, D-85747 Garching, Germany \\ ${ }^{4}$ Institute of Chemical Technologies and Analytics, Technische Universität Wien, A-1060 Vienna, Austria \\ ${ }^{5}$ Institute for Materials Research, Helmholtz-Zentrum Geesthacht, D-21502 Geesthacht, Germany
}

(Received 20 December 2019; accepted 14 May 2020; published 26 June 2020)

\begin{abstract}
Experiments are reported, which allow us to quantify the near-surface cation diffusion in (001) oriented $\mathrm{Fe}_{3} \mathrm{O}_{4}$ single crystals at temperatures between 470 and $770 \mathrm{~K}$. Thin homoepitaxial films of magnetite, grown using isotopically labeled ${ }^{57} \mathrm{Fe}$, were investigated by neutron reflectivity and time-of-flight secondary ion mass spectrometry. By heating the thin films in high vacuum to different temperatures for a well-defined time and determining the ${ }^{57} \mathrm{Fe}$ distribution along the surface normal, the diffusion lengths are obtained. For the investigated temperature range, diffusion constants of the order of $10^{-20} \mathrm{~m}^{2} / \mathrm{s}$ are deduced. These results are important in view of near-surface mass transport induced by oxygen chemical potential differences occurring when magnetite is exposed to different gas atmospheres or by adsorbates.
\end{abstract}

DOI: 10.1103/PhysRevResearch.2.023406

\section{INTRODUCTION}

Iron oxides are used in catalysis, material science, and in the development of spintronic devices [1]. As corrosion products, iron sources, and pigments, iron oxides are known for centuries [1,2]. Magnetite $\left(\mathrm{Fe}_{3} \mathrm{O}_{4}\right)$ was one of the first known magnetic materials and gave rise to the discovery of ferrimagnetism [3]. It also proved to be an excellent catalyst for the water-gas-shift reaction $\left(\mathrm{CO}+\mathrm{H}_{2} \mathrm{O} \rightarrow \mathrm{H}_{2}+\mathrm{CO}_{2}\right)$ [4] as well as the Fischer-Tropsch synthesis [5]. More recently, $\mathrm{Fe}_{3} \mathrm{O}_{4}$ was proposed as a material for spintronics, even though the application is still challenging because of interface effects $[1,2,6-8]$. Due to the good control of the synthesis process and the wide functionalization possibilities, $\mathrm{Fe}_{3} \mathrm{O}_{4}$ nanoparticles are used to assemble hierarchically structured materials of superior mechanical properties $[9,10]$. The electronic characteristics in spintronic applications and the adsorption behavior of molecules like educts in catalytic reactions or nanoparticle's ligands strongly depend on the surface chemistry of $\mathrm{Fe}_{3} \mathrm{O}_{4}$ [1]. To tune the material's properties for these applications, a precise description of the processes at the magnetite surface and its interfacial chemistry is necessary $[1,11]$. These processes include alterations of the $\mathrm{Fe}_{3} \mathrm{O}_{4}$ surface through near-surface mass transport [12-14].

\footnotetext{
*andreas.stierle@desy.de

Published by the American Physical Society under the terms of the Creative Commons Attribution 4.0 International license. Further distribution of this work must maintain attribution to the author(s) and the published article's title, journal citation, and DOI.
}

Magnetite $\left(\mathrm{Fe}_{3} \mathrm{O}_{4}\right)$ consists of a face centered cubic (fcc) oxygen sublattice containing $\mathrm{Fe}^{3+}$ in $1 / 8$ of the tetrahedral lattice sites and $\mathrm{Fe}^{3+}$ and $\mathrm{Fe}^{2+}$ occupying 1/4 of the octahedral lattice sites, each. Above the Verwey temperature of $125 \mathrm{~K}$, the charge of the octahedral cations can be considered as equivalent to $\mathrm{Fe}_{\mathrm{oct}}^{+2.5}$ due to electron hopping in the octahedral sublattice $\left(\mathrm{Fe}^{3+}+e^{-} \rightleftharpoons \mathrm{Fe}^{2+}\right)[1,15]$. While the Verwey temperature is highly sensitive to the chemical composition, the inverse spinel structure of magnetite tolerates minor deviations from the ideal stoichiometry [16]. Under ultrahigh vacuum (UHV), a $(\sqrt{2} \times \sqrt{2}) \mathrm{R} 45^{\circ}$ surface reconstruction is formed on the (001) surface [1]. Having one extra interstitial tetrahedral $\mathrm{Fe}$ ion and two octahedral subsurface $\mathrm{Fe}$ vacancies the so-called subsurface cation vacancy stabilized (SCV) surface is nonstoichiometric with one net iron vacancy per unit cell $[12,13]$. The reconstruction is reported to get lifted upon water, formic acid, and atomic hydrogen adsorption at room temperature, in line with a reduction of the surface [13,17-20]. Observations by low energy electron microscopy (LEEM) revealed a regrowth of many $\mathrm{Fe}_{3} \mathrm{O}_{4}$ layers upon exposure of the surface to $1.3 \times 10^{-6}$ mbar oxygen at $1000 \mathrm{~K}$ by diffusion of Fe cations to the surface [14]. Regrowth and the formation and lifting of the surface reconstruction involve near-surface diffusion of iron cations at low temperatures. The details are so far not well understood. To the best of our knowledge, cation diffusion in magnetite has been studied only in the bulk at temperatures above $770 \mathrm{~K}$ [21].

Experiments on bulk diffusion using ${ }^{59} \mathrm{Fe}$ and ${ }^{55} \mathrm{Fe}$ as a radioactive tracer for depth profiling were carried out for bulk $\mathrm{Fe}_{3} \mathrm{O}_{4}$ in a temperature range between 1170 and $1670 \mathrm{~K}$. The oxygen activity $a_{\mathrm{O}_{2}}$ was varied from reducing to oxidizing conditions in these experiments. From the results, 
the point defect model for diffusion in $\mathrm{Fe}_{3} \mathrm{O}_{4}$ with different diffusion pathways for reducing and oxidizing conditions was developed by Dieckmann and Schmalzried [22-25]. The model was confirmed experimentally by Mössbauer spectroscopy and tracer diffusion experiments for temperatures as low as $770 \mathrm{~K}[21,26,27]$. A theoretical verification with a description for the low temperature region was given by computer coupling of phase diagrams and thermochemistry (CALPHAD) [28]. Under oxidizing conditions at elevated oxygen pressures, cation vacancies are reported to be the predominant defects in magnetite [29]. Transport processes are therefore proposed to be mediated via a vacancy mechanism with cations moving through the crystal by hopping to neighboring vacant sites [22,23]. Under reducing conditions in the absence of oxygen, Frenkel pairs, the combination of a cation vacancy at a regular lattice site and an interstitial atom, are the predominant defects. In this regime, cation motion is proposed to be mediated via an interstitial mechanism with cations hopping along interstitial sites or, more likely, an interstitialcy mechanism [27]. In the interstitialcy mechanism, interstitial cations replace cations on regular lattice sites which simultaneously become interstitial cations [30]. The vacancy formation was found to scale with the oxygen activity as $a_{\mathrm{O}_{2}}{ }^{2 / 3}$ and the oxygen activity dependence for interstitial formation as ${a_{\mathrm{O}_{2}}}^{-2 / 3}[22,23,29]$. The formation enthalpy of cation vacancies in $\mathrm{Fe}_{3} \mathrm{O}_{4}$ under oxidizing conditions is negative [31], shifting the chemical equilibrium to a lower number of cation vacancies for increasing temperatures and constant oxygen pressures. Despite the higher mobility of the vacancies for increasing temperatures, the cation motion via the vacancy mechanism is decelerated due to the reduced number of defects for increasing temperatures and constant $a_{\mathrm{O}_{2}}$ resulting in a negative effective activation energy for the vacancy process $[31,32]$. Accordingly, the transition point from the vacancy to the interstitial mechanism is temperature dependent and shifts to higher temperatures for increasing oxygen pressures. The formation enthalpy of interstitials in oxidizing and reducing conditions is in contrast strongly positive. With the enhanced mobility of interstitials for higher temperatures, this leads to an acceleration of the interstitial diffusion at increasing temperatures [29]. Mössbauer spectroscopy studies showed that the vacancy mechanism mainly involves octahedral cations and vacancies, while the interstitial and interstitialcy mechanism predominantly involves tetrahedral cations and vacancies. The diffusion process can be considered to be charge independent as the observations were made well above the Verwey temperature [26,27]. In a recent DFT study the vacancy diffusion within the octahedral lattice was studied at $1073 \mathrm{~K}$. For the hopping between two octahedral lattice sites, an activation energy of $0.70 \mathrm{eV}$ was calculated with an activation energy of $0.65 \mathrm{eV}$ to hop to an intermediate tetrahedral site and further $0.05 \mathrm{eV}$ to hop to a stable octahedral position [33]. The influence of oxygen transport is small compared to the iron transport, as oxygen anions form a rather perfect fcc lattice for stoichiometries from $\mathrm{FeO}$ to $\gamma-\mathrm{Fe}_{2} \mathrm{O}_{3}[26,29]$.

While the bulk cation diffusion at high temperatures is extensively studied and quite-well understood, the transport processes at low temperatures and particularly around the near-surface region are still largely unknown. A better knowl-

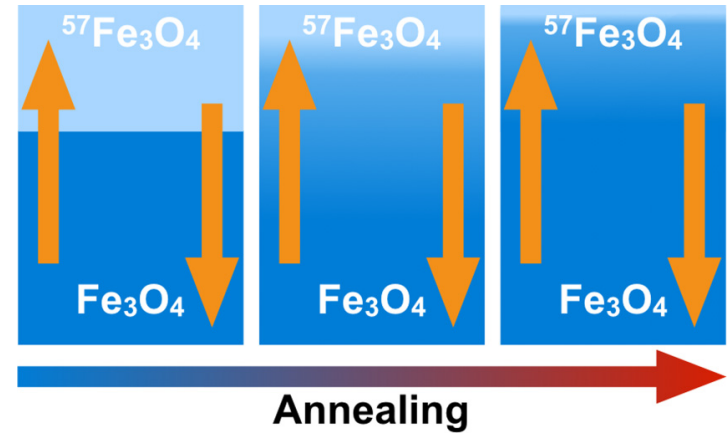

FIG. 1. Schematic description of the experimental procedure. By subsequent annealing steps, the originally sharp interface between the ${ }^{57} \mathrm{Fe}_{3} \mathrm{O}_{4}$ thin film and the substrate is more and more smeared out resulting in an increased roughness of the isotopic composition profile. The isotope distribution is determined by neutron reflectivity and time-of-flight secondary ion mass spectrometry (ToF-SIMS).

edge of near-surface diffusion processes is particularly important since devices utilizing surfaces and thin films are the main objects for applications in catalysis and spintronics. Making use of the specific neutron scattering lengths of different isotopes near-surface diffusion can be studied at the nanometer scale using neutron reflectivity. The determination of diffusion lengths below $1 \mathrm{~nm}$ was reported for isotopic $\mathrm{Si}^{14} \mathrm{~N} / \mathrm{Si}^{15} \mathrm{~N}$ and ${ }^{57} \mathrm{Fe} /{ }^{56} \mathrm{Fe}$ multilayer systems [34-37]. In this kind of experiment, the depth resolution depends on the quality of the interface between the substrate and the isotope film. The interfacial roughness between the isotopically labeled layers has to be small to allow neutron interference effects at the isotope interface while a chemically homogenous sample is needed to model the diffusion correctly.

Here isotopically labeled ${ }^{57} \mathrm{Fe}_{3} \mathrm{O}_{4}$ thin films grown homoepitaxially on (001)-oriented natural $\mathrm{Fe}_{3} \mathrm{O}_{4}$ crystals by reactive molecular beam epitaxy (MBE) were used to study the near-surface cation diffusion in magnetite in the catalytically relevant temperature range between 470 and $770 \mathrm{~K}$ [11]. The growth conditions of the thin films were chosen in order to achieve a chemically nearly homogenous sample and the lowest possible intermixing of ${ }^{57} \mathrm{Fe}$ and substrate during the sample preparation. Taking advantage of the different neutron scattering lengths of iron in the natural isotopic composition ${ }^{n a t} \mathrm{Fe}(b=9.45 \mathrm{fm})$ and ${ }^{57} \mathrm{Fe}(b=2.31 \mathrm{fm})$ [38], the diffusion process perpendicular to the sample surface was followed by neutron reflectivity (NR) averaging over the complete sample surface after subsequent annealing steps (see Fig. 1). Complementary time-of-flight secondary ion mass spectrometry (ToF-SIMS) depth profiling was conducted after the neutron experiments to obtain direct and more local information about the ${ }^{57} \mathrm{Fe}$ distribution. We observed cation interdiffusion at temperatures as low as $470 \mathrm{~K}$ and estimated near-surface cation diffusion coefficients in the order of $10^{-20} \mathrm{~m}^{2} / \mathrm{s}$. Our observations indicate the presence of a low temperature nearsurface diffusion process as proposed in conjunction with the formation and lifting of the $(\sqrt{2} \times \sqrt{2}) \mathrm{R}_{4} 5^{\circ}$ surface reconstruction on $\mathrm{Fe}_{3} \mathrm{O}_{4}(001)$ [18] and a recently observed reversible order-disorder phase transition upon heating the $\mathrm{Fe}_{3} \mathrm{O}_{4}(001)$ surface [19]. 


\section{EXPERIMENTAL DETAILS}

\section{A. Thin-film growth}

Epitaxial ${ }^{57} \mathrm{Fe}_{3} \mathrm{O}_{4}$ thin films were grown by molecular beam epitaxy (MBE) in the UHV system of the DESY NanoLab [39] with a base pressure in the growth chamber of $3 \times 10^{-11}$ mbar. The growth chamber is equipped with a low energy electron diffraction (LEED) and Auger electron spectroscopy (AES) system. A $(\sqrt{2} \times \sqrt{2}) \mathrm{R} 45^{\circ}$ reconstructed (001) surface was prepared on (001) oriented natural single crystalline $\mathrm{Fe}_{3} \mathrm{O}_{4}$ substrates $\left(10 \times 10 \mathrm{~mm}\right.$, miscut $\left.<0.1^{\circ}\right)$ by multiple cycles of $\mathrm{Ar}^{+}$sputtering at $5 \times 10^{-6}$ mbar at $1 \mathrm{keV}$ and subsequent annealing at $930 \mathrm{~K}$ in UHV. The final annealing step was carried out in $1 \times 10^{-6}$ mbar oxygen as described elsewhere $[12,13]$. The thin films were grown from a ${ }^{57} \mathrm{Fe}$ rod $(99.99 \%$ chemical purity, enriched to $>95 \%$ ${ }^{57} \mathrm{Fe}$ ) heated by electron bombardment at a growth rate of $0.025 \AA / \mathrm{s}$ in $4 \times 10^{-6}$ mbar oxygen (99.999\% purity) at a substrate temperature of $420 \mathrm{~K}$. Iron flux and pressure were kept constant $( \pm 5 \%)$ during deposition, the heating station was precalibrated for conducting substrates using a $\mathrm{Ni}-\mathrm{CrNi}$ thermocouple. The growth rate was precalibrated by $\mathrm{x}$-ray reflectivity measurements of a test sample on $\mathrm{Al}_{2} \mathrm{O}_{3}$.

\section{B. Post-growth characterization and annealing}

The samples were precharacterized by LEED and AES directly after growth before being transferred to air. For the $\mathrm{X}$-ray photoelectron spectroscopy (XPS) measurements, the sample was transferred at ambient conditions and measured in the XPS system at DESY NanoLab [39]. The measurements were carried out using a high-resolution two-dimensional delay line detector. Spectra were recorded in fixed transmission mode using a monochromatic $\mathrm{Al} K_{\alpha}$ x-ray source (photon energy $1486.6 \mathrm{eV} / \lambda=8.34 \AA$; anode operating at $15 \mathrm{kV}$ ). A pass energy of $20 \mathrm{eV}$ was chosen, providing an overall energy resolution better than $0.4 \mathrm{eV}$. Charging effects were compensated by using a flood gun. The binding energies were calibrated based on the graphitic carbon $1 s$ peak at $284.8 \mathrm{eV}$. $\mathrm{X}$-ray reflectivity (XRR) measurements were carried out ex situ before and after the diffusion experiment with a commercial x-ray diffraction system in $\theta / 2 \theta$ geometry using $\mathrm{Cu}$ $K_{\alpha}$ radiation $(\lambda=1.54051 \AA)$ at the DESY outstation of the Helmholtz Zentrum Geesthacht (HZG). The cation diffusion was induced by annealing in UHV in the MBE system at the Jülich Center of Neutron Science (JCNS), Garching outstation with a base pressure in the $10^{-9}$ mbar range. After a warmup period of $10 \mathrm{~min}$, the samples were kept at the desired temperature for $15 \mathrm{~min}$. During annealing pressure rose up to $1.2 \times 10^{-7}$ mbar, most likely resulting from water adsorbed on the sample and the sample holder. The temperature was controlled by a thermocouple at the heating station. Sample transfer to the neutron instrument was performed under ambient conditions.

\section{Neutron reflectivity}

Neutron reflectivity (NR) studies were carried out ex situ in ambient atmosphere at the MARIA instrument of the Jülich Centre for Neutron Science (JCNS) at the Heinz MaierLeibnitz Zentrum (MLZ) in Garching [40,41]. The reflec- tometer is operated in an angular dispersive $\theta / 2 \theta$ mode with the neutron beam monochromatized by a velocity selector with an energy resolution of $10 \%$ [40]. To optimize flux and resolution, the reflectivity curves were acquired at a wavelength of $10 \AA$ until $q=0.0395 \AA^{-1}\left(1.8^{\circ}\right)$ and at $5 \AA$ from $q=0.0351 \AA^{-1}\left(0.8^{\circ}\right)$ to the highest measured momentum transfer $q$ derived by $q=\frac{4 \pi}{\lambda} \sin (\theta)$ with the incident angle $\theta$. Integration times for the low $q$ regime were between 30 and $350 \mathrm{~s}$, for the high $q$ regime between 300 and $550 \mathrm{~s}$ at an angular resolution of $0.05^{\circ}$. For evaluation, the data were footprint corrected.

\section{ToF-SIMS}

For measuring ToF-SIMS depth profiles the samples were introduced into a UHV chamber with a pressure of $2 \times 10^{-8}$ mbar at TU Wien after the neutron experiments. Bombarded with a pulsed $25 \mathrm{kV} \mathrm{Bi}_{1}^{+}$ion beam the sample emits positive secondary ions which are extracted to the ToF analyzer. The material was eroded by a continuous $2 \mathrm{kV}$ $\mathrm{O}_{2}^{+}$ion beam. The analysis was performed with interlaced settings of the primary gun, sputter gun, and analyzer in highcurrent-bunched mode to provide a good mass resolution. The measurements were obtained in an area of $100 \times 100 \mu \mathrm{m}^{2}$ with a spatial resolution of $64 \times 64$ pixels. This field of view was centered into a sputtered crater of $300 \times 300 \mu \mathrm{m}^{2}$. For the charge compensation the analysis area was flooded with a $21 \mathrm{~V}$ electron gun. The depth calibration of the ToF-SIMS measurement was done with a mechanical profilometer to correlate the sputter time with depth of the sputter crater.

\section{RESULTS AND DISCUSSION}

\section{A. Growth of $\mathrm{Fe}_{3} \mathrm{O}_{4}$ on $\mathrm{Fe}_{3} \mathrm{O}_{4}(100)$}

Based on procedures established for the growth of $\mathrm{Fe}_{3} \mathrm{O}_{4}$ on $\mathrm{MgO}$, the homoepitaxial growth of $\mathrm{Fe}_{3} \mathrm{O}_{4}$ on $\mathrm{Fe}_{3} \mathrm{O}_{4}$ was performed. A relatively high oxygen pressure of $4 \times 10^{-6}$ mbar was chosen for the film preparation to prevent the deposition of metallic iron within the films [42-44]. Growth studies of $\mathrm{Fe}_{3} \mathrm{O}_{4}$ on $\mathrm{MgO}$ suggest that interfacial diffusion during growth increases at temperatures above $520 \mathrm{~K}$, indicating already significant cation exchange [45]. Growth experiments on $\mathrm{Fe}_{3} \mathrm{O}_{4}$ single crystals were therefore performed in a temperature range from room temperature up to approximately $520 \mathrm{~K}$, a temperature commonly chosen for the growth of $\mathrm{Fe}_{3} \mathrm{O}_{4}$ on $\mathrm{MgO}[44,45]$. Auger-electron spectra (AES) of the as-prepared crystal and thin films deposited at room temperature [see Fig. 2(a)], 420, and $520 \mathrm{~K}$ consistently show a double peak instead of a sharp iron MNN line suggesting the absence of metallic iron and formation of iron oxide [46]. Nevertheless, a $(\sqrt{2} \times \sqrt{2}) \mathrm{R} 45^{\circ}$ reconstruction as formed on the clean substrate [see Fig. 2(b)] was only observed by LEED for films grown at $520 \mathrm{~K}$ [see Fig. 2(c)] and slightly weakened for the films grown at $420 \mathrm{~K}$ [see Fig. 2(d)]. The sample grown at room temperature was unreconstructed with a clearly visible $(1 \times 1)$ unit cell pattern of $\mathrm{Fe}_{3} \mathrm{O}_{4}$ [see Fig. 2(e)]. X-ray photoelectron spectra (XPS) of a thin film grown at $420 \mathrm{~K}$ at a reduced oxygen pressure of $8 \times 10^{-7}$ mbar showed a good agreement in the signature 

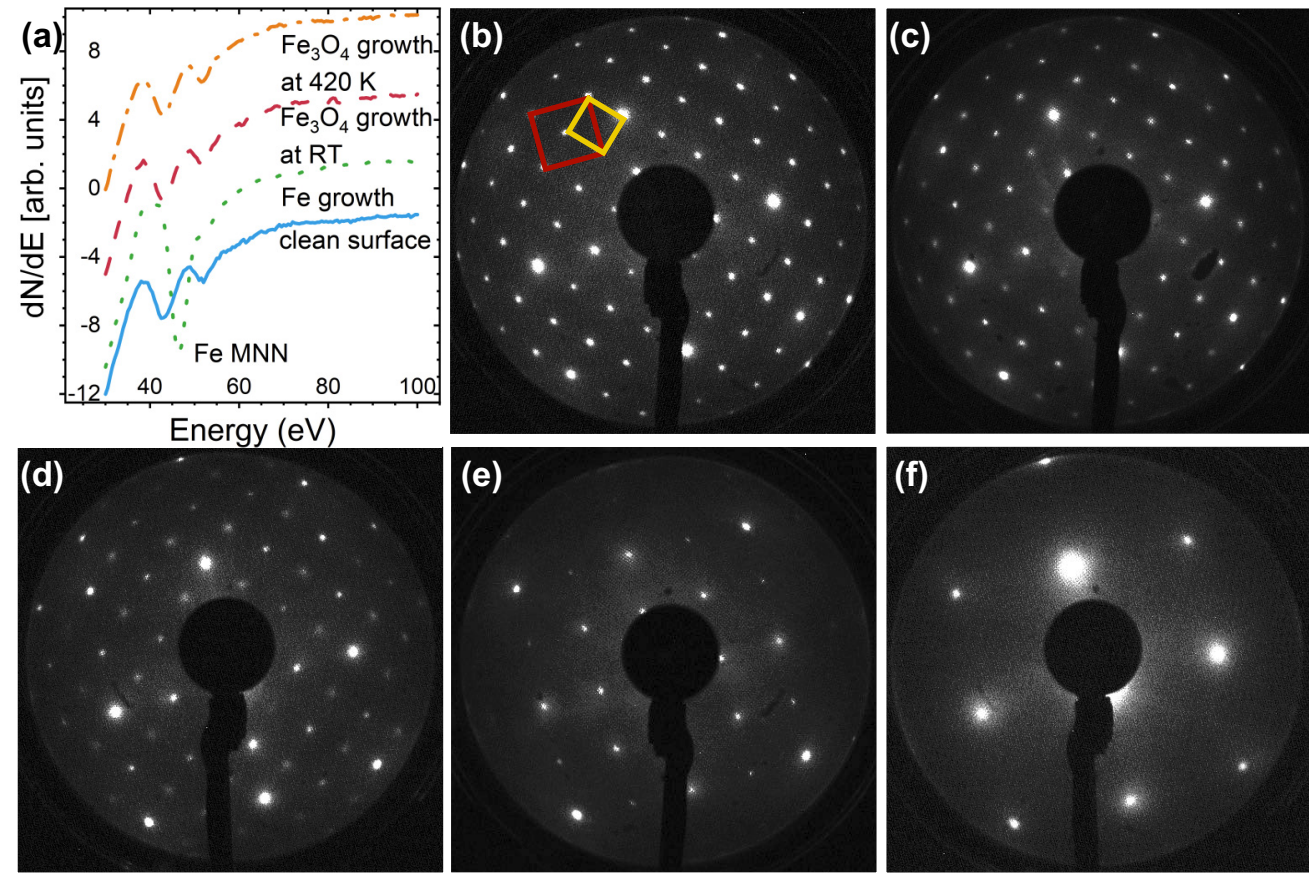

FIG. 2. AES measurements and LEED patterns at $100 \mathrm{eV}$ of $\mathrm{Fe}_{3} \mathrm{O}_{4}$ films grown on $\mathrm{Fe}_{3} \mathrm{O}_{4}$ (001) substrates. (a) AES of the clean surface (blue solid line), the Fe film (green dotted line), the $\mathrm{Fe}_{3} \mathrm{O}_{4}$ film grown at room temperature (red dashed line), and the $\mathrm{Fe}_{3} \mathrm{O}_{4}$ film grown at $420 \mathrm{~K}$ (orange dashed-dotted line). The curves are displaced for the sake of clarity. (b) LEED pattern of the clean $(\sqrt{2} \times \sqrt{2}) \mathrm{R} 45^{\circ}$ reconstructed substrate surface. The $(1 \times 1)$ and $(\sqrt{2} \times \sqrt{2})$ unit cells are highlighted in red and yellow. (c)-(e) LEED patterns of thin films grown at $520 \mathrm{~K}$, $420 \mathrm{~K}$, and room temperature, respectively. No reconstruction was observed for the sample grown at room temperature, while the reconstruction spots are clearly visible for the clean surface and the samples grown at 420 and $520 \mathrm{~K}$. (f) LEED pattern of a pure Fe(100) film grown at room temperature for comparison.

of the $2 p$ core level compared to the one of the pure $\mathrm{Fe}_{3} \mathrm{O}_{4}$ substrate (see Fig. S4 in the Supplemental Material [47]).

The results of the growth studies were crosschecked by growing a pure iron film at room temperature in the absence of oxygen. Already for film thicknesses of less than $10 \AA$, the smaller unit cell of Fe (001) [48] was observed by LEED in Fig. 2(f) and the Fe MNN line observed by AES indicated the presence of metallic iron on the surface as shown in Fig. 2(a). The deposition of larger quantities of metallic iron in oxygen atmosphere which might influence the near-surface diffusion is therefore unlikely.

Two samples of different thicknesses were prepared for the diffusion experiments (sample A: $175 \AA$ A, sample B: $248 \AA$ ). A deposition temperature of $420 \mathrm{~K}$ was chosen to reduce interdiffusion during deposition by lowering the temperature while ensuring a stoichiometry close to $\mathrm{Fe}_{3} \mathrm{O}_{4}$. For AES and LEED data of samples A and B see Figs. S1, S2, and S3 in the Supplemental Material [47]. Weak oscillations were observed in the $\mathrm{x}$-ray reflectivities (XRR) of samples A and B [see Figs. 3(a) and 3(b)]. Assuming a sample structure consisting of the $\mathrm{Fe}_{3} \mathrm{O}_{4}$ substrate, a ${ }^{57} \mathrm{Fe}_{3} \mathrm{O}_{4}$ layer with a slightly reduced density, a surface layer with a further reduced density, and a layer of adsorbed water, the XRR data were fitted using Parratt's formalism [49]. As the oscillations in the XRR of sample B had vanished after annealing, this curve was fitted with only one ${ }^{57} \mathrm{Fe}_{3} \mathrm{O}_{4}$ layer. For all curves, the fit parameters can be found in Table S1 in the Supplemental Material [47]. Thicknesses of 175 and $248 \AA$ of the ${ }^{57} \mathrm{Fe}_{3} \mathrm{O}_{4}$ layers on samples A and B, respectively, were obtained from the fit. The fitted electron density profiles show a slightly reduced electron density in the deposited film compared to the substrate [see Figs. 3(a) and 3(b) inset] with electron density differences of $3 \%$ for sample A and $4 \%$ for sample B. From the electron density difference a cation deficit in the layers of up to $7 \%$ was calculated, probably resulting from morphological or stoichiometric deviations of the film and the substrate. These deviations probably were caused by the comparatively high $\mathrm{O}_{2}$ pressure in the deposition process. The inverse spinel structure of magnetite tolerates stoichiometric deviations [16], however the presence of the $(\sqrt{2} \times \sqrt{2}) \mathrm{R} 45^{\circ}$ surface reconstruction observed by LEED suggests that the deposited ${ }^{57} \mathrm{Fe}$ formed an epitaxial $\mathrm{Fe}_{3} \mathrm{O}_{4}$ film on the substrate. The interfacial and surface roughnesses seemed to increase after annealing while the electron density differences between film and substrate altered slightly for both samples. No systematic change was observed for the water layer resulting from air humidity. Nevertheless, reactions with adsorbed water might have caused the surface roughening observed after annealing [19].

\section{B. Neutron reflectivity}

The large scattering length density (SLD) difference between the ${ }^{57} \mathrm{Fe}_{3} \mathrm{O}_{4}$ film $\left(\mathrm{SLD}=0.407 \mathrm{fm} / \AA^{3}\right)$ and the $\mathrm{Fe}_{3} \mathrm{O}_{4}$ substrate ( $\mathrm{SLD}=0.697 \mathrm{fm} / \AA^{3}$ ) [38] is expected to result in distinct oscillations in the NR of the samples A and B (see simulations in Figs. S5 and S6 in the Supplemental Material [47]). In the course of the annealing steps, these 
(a)

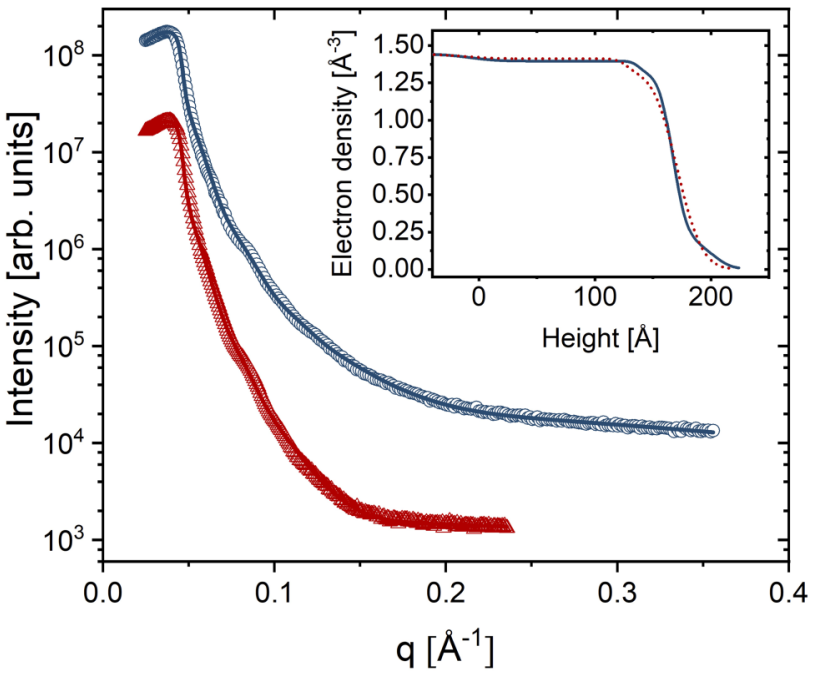

(b)

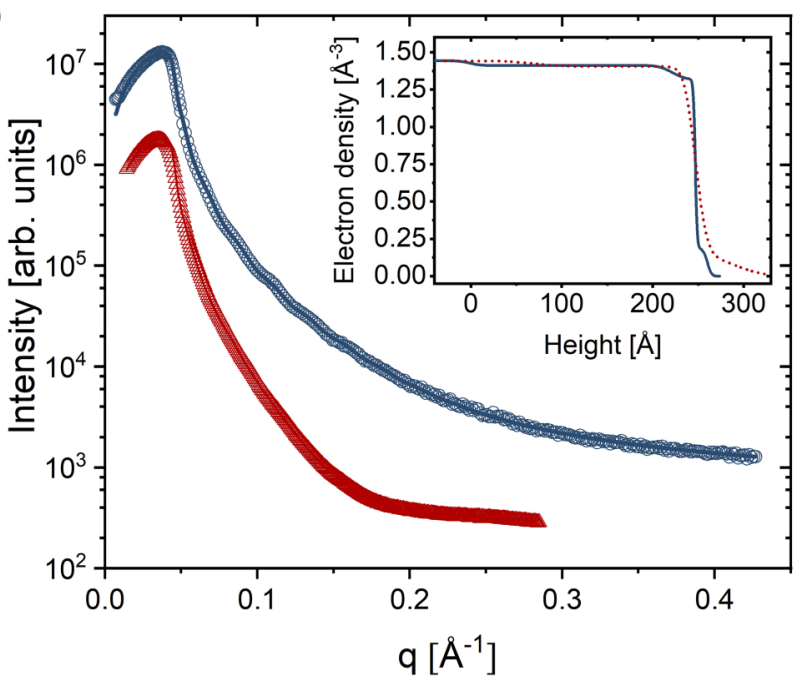

FIG. 3. XRR and electron density profiles (insets) of (a) sample A before (blue circles, fit solid line, displaced by a factor of 10) and after (red triangles, fit solid line) annealing at $470 \mathrm{~K}$ in UHV and (b) sample B before (blue circles, fit solid line) and after (red triangles, fit solid line) annealing at 470, 570, 670, and $770 \mathrm{~K}$ in UHV. Weak oscillations of the reflectivities and the fitted electron density profiles indicate a density difference between films and substrates before (blue solid lines) and after (red dotted lines) the diffusion experiments. For both samples, the surface notably roughened after UHV annealing.

oscillations are expected to fade out due to the intermixing of cations of the film and the substrate. A notable damping of the oscillations' amplitudes observed in the NR curves measured before the annealing procedure indicated a rather blurred interfacial distribution of ${ }^{57} \mathrm{Fe}$ already at the start of the neutron scattering experiment (see Figs. 4 and 5). The isotopically rough interface likely resulted from interdiffusion processes over the whole film thickness during the ${ }^{57} \mathrm{Fe}$ deposition at temperatures of about $420 \mathrm{~K}$. This effect at comparatively low temperatures might be related to the sensitive balance of $\mathrm{O}_{2}$ pressure and ${ }^{57} \mathrm{Fe}$ deposition rate during the growth to obtain a stoichiometric film. A regrowth process comparable to the process described in [14] for annealing at about $800 \mathrm{~K}$ and $1.3 \times 10^{-6}$ mbar $\mathrm{O}_{2}$ might have taken place in parallel to

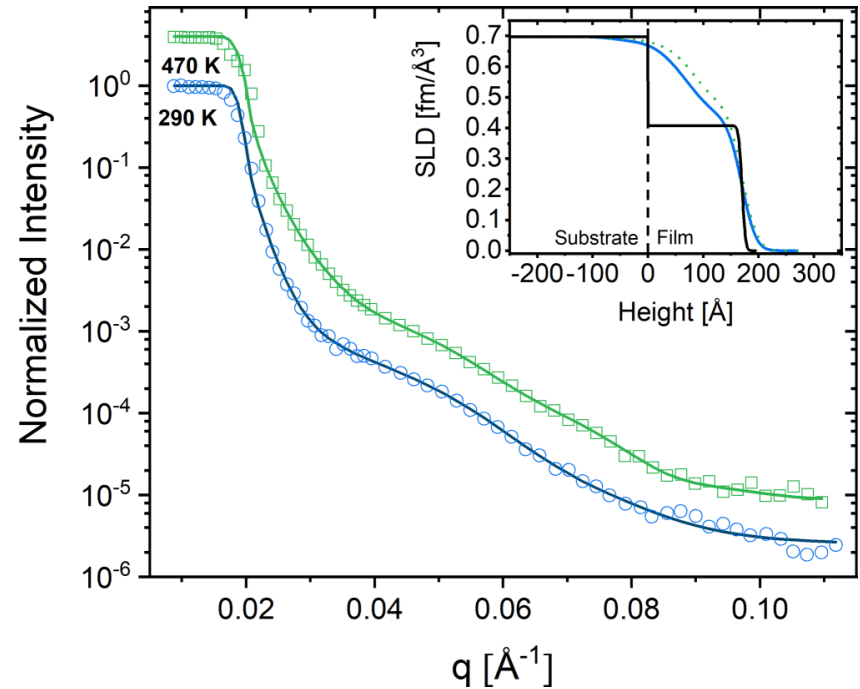

FIG. 4. NR curves and fits of sample $\mathrm{A}\left(175 \AA{ }^{57} \mathrm{Fe}_{3} \mathrm{O}_{4}\right.$ layer on natural $\mathrm{Fe}_{3} \mathrm{O}_{4}$ ) before (blue circles/blue solid line) and after UHV annealing at $470 \mathrm{~K}$ (green squares/green solid line). The curve's maximum intensities were normalized to 1 and the curve after annealing was shifted by a factor of 4 for the sake of clarity. SLD profiles (inset) before annealing (blue solid line) and after annealing (green dotted line) were obtained from the NR curves. The SLD profile of an ideally flat ${ }^{57} \mathrm{Fe}_{3} \mathrm{O}_{4} / \mathrm{Fe}_{3} \mathrm{O}_{4}$ interface is shown in black.

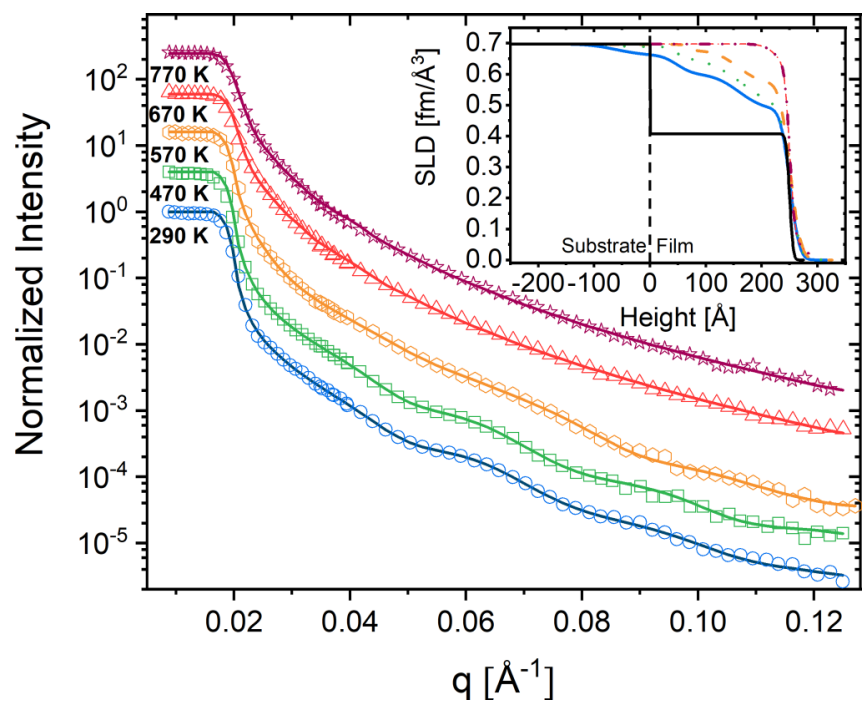

FIG. 5. NR curves and fits of sample $\mathrm{B}\left(248 \AA{ }^{57} \mathrm{Fe}_{3} \mathrm{O}_{4}\right.$ layer on natural $\mathrm{Fe}_{3} \mathrm{O}_{4}$ ) before (blue circles/blue solid line) and after subsequent UHV annealing steps at $470 \mathrm{~K}$ (green square/solid line), $570 \mathrm{~K}$ (yellow hexagons/solid line), $670 \mathrm{~K}$ (orange triangles/solid line), and $770 \mathrm{~K}$ (red stars/solid line). The curve's maximum intensities were normalized to 1 and for the sake of clarity, the curves after annealing to $470,570,670$, and $770 \mathrm{~K}$ were shifted by factors of $4,16,64$, and 256, respectively. SLD profiles (inset) were fitted to the NR curves. They are shown for the state before annealing (blue solid line), and after annealing to $470 \mathrm{~K}$ (green dotted line), $570 \mathrm{~K}$ (yellow dashed line), $670 \mathrm{~K}$ (orange dashed-dotted line), and $770 \mathrm{~K}$ (red dashed-double-dotted line), respectively. The SLD profile of an ideally flat ${ }^{57} \mathrm{Fe}_{3} \mathrm{O}_{4} / \mathrm{Fe}_{3} \mathrm{O}_{4}$ interface is shown in black. 
the deposition of ${ }^{57} \mathrm{Fe}$ at $420 \mathrm{~K}$ in $4 \times 10^{-6} \mathrm{mbar}^{\mathrm{O}}$ and explains the notable intermixing of the iron isotopes at the film-substrate interface observed for both samples. However, the density difference of film and substrate observed by XRR after preparation indicates that no complete stoichiometric equilibration between the layers took place. The thin film either contains a high number of crystallographic defects or the morphology of the film was not perfect reducing its average density.

The NR curves were fitted using GenX [50] modeling the SLD profile by three layers and $\mathrm{Fe}_{3} \mathrm{O}_{4}$ substrate taking into account the observed roughness effects. The layers represent the three zones of the film: the interdiffusion zone of the substrate where ${ }^{57} \mathrm{Fe}$ was incorporated during the growth, the mixed zone of the thin film, where iron from the substrate was incorporated into the film, and the undisturbed zone at the surface, which consists of nearly pure ${ }^{57} \mathrm{Fe}_{3} \mathrm{O}_{4}$. The fit parameters are shown in Tables $\mathrm{S} 2$ and $\mathrm{S} 3$ in the Supplemental Material [47], respectively.

The NR of sample A (see Fig. 4) contained a single oscillation at about $q=0.05 \AA^{-1}$. After annealing at $470 \mathrm{~K}$ in UHV for $15 \mathrm{~min}$, a minor damping of the oscillation's amplitude and a small shift of the oscillation to higher $q$ values were observed in NR indicating a slight further roughening of the film-substrate interface and a decreasing effective thickness of the ${ }^{57} \mathrm{Fe}_{3} \mathrm{O}_{4}$ film caused by ${ }^{57} \mathrm{Fe}$ diffusion into the substrate. Before annealing the fitted SLD at the surface of sample A was identical to the SLD of ${ }^{57} \mathrm{Fe}_{3} \mathrm{O}_{4}\left(0.407 \mathrm{fm} / \AA^{3}\right)$. From the surface, the SLD increased approximately linearly throughout the film to $0.698 \mathrm{fm} / \AA^{3}$. This is identical to the SLD of $\mathrm{Fe}_{3} \mathrm{O}_{4}$ of the natural isotopic composition (see Fig. 4, inset). The linear slope of the SLD profile with rough interfacial regions points towards an intermixing of ${ }^{57} \mathrm{Fe}$ and Fe ions during growth in contrast to the relatively sharp interface as observed by XRR for the electron density [see Fig. 3(a)]. After annealing, the overall SLD increased as a result of the diffusion of natural Fe into the film. The slope in the profile became steeper due to the smaller effective film thickness.

Sample B was subsequently heated to 470, 570, 670, and $770 \mathrm{~K}$ for $15 \mathrm{~min}$ each. Neutron reflectivities measured ex situ after each annealing step showed a progressive damping of the oscillations until a Fresnel-like curve without any observable oscillation appeared after heating to $670 \mathrm{~K}$ (see Fig. 5). Further heating to $770 \mathrm{~K}$ yielded no change of the reflectivity. The oscillations slightly shifted towards higher $q$ values, suggesting a decrease of the ${ }^{57} \mathrm{Fe}_{3} \mathrm{O}_{4}$-film thickness during the annealing process. The SLD profile fitted to the NR before annealing (see Fig. 5 inset) had a layered structure. After increasing linearly from the sample surface to a plateau at $0.6 \mathrm{fm} / \AA^{3}$ the SLD increased to the SLD of natural $\mathrm{Fe}_{3} \mathrm{O}_{4}$. The profile's shape reflects the three layers assumed in the fitting procedure. Annealing the sample at $470 \mathrm{~K}$ for $15 \mathrm{~min}$ in UHV had a small but significant effect. The overall increase of the SLD while maintaining the profiles's three zones suggests a uniform diffusion of the iron cations from the bulk up to the sample surface. Annealing to $570 \mathrm{~K}$ lead to a notable increase of the scattering length density throughout the film. After the annealing to 670 and $770 \mathrm{~K}$ nearly identical flat SLD profiles were observed, indicating an equilibration of the ${ }^{57} \mathrm{Fe}$ concentrations in the film and the bulk after the annealing step to $670 \mathrm{~K}$. The characteristic shape of the SLD profile disappeared as cations from the substrate reached the film surface. The curves measured after annealing to 670 and $770 \mathrm{~K}$ were therefore fitted with a model consisting only of a substrate and one layer instead of three.

For both samples A and B, a nearly uniform diffusion front of mainly ${ }^{56} \mathrm{Fe}$ cations from the substrate into the film was observed for the different annealing temperatures. Hence an inwards diffusion of ${ }^{57} \mathrm{Fe}$ into the substrate is the logical consequence.

\section{ToF-SIMS}

After the annealing experiments, complementary time-offlight-secondary ion mass spectroscopy profiling (ToF-SIMS) of both samples in their final state was carried out. ToF-SIMS profiling of sample A showed a decreasing ${ }^{57} \mathrm{Fe}$ signal from the sample surface towards the bulk after being annealed at $470 \mathrm{~K}$ for $15 \mathrm{~min}$ in UHV [see Fig. 6(a)]. This observation is in agreement with the NR results showing an increase of the SLD within the film from the surface to the substrate due to the decreasing concentration of ${ }^{57} \mathrm{Fe}$. A reduced overall intensity in the near-surface region corresponds well to the film thickness supporting the assumption of a reduced density of the film previously made based on the XRR measurements. For sample B which was in total heated for $60 \mathrm{~min}$ at temperatures up to $770 \mathrm{~K}$, the ToF-SIMS profile is nearly flat [see Fig. 6(b)]. NR and ToF-SIMS consistently show that the

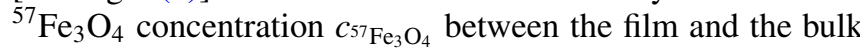
equilibrated after the annealing procedure. For ToF-SIMS, ${ }^{C}{ }^{57} \mathrm{Fe}_{3} \mathrm{O}_{4}$ at a given position is calculated via Eq. (1):

$$
C_{57} \mathrm{Fe}_{3} \mathrm{O}_{4}=\frac{I_{57} \mathrm{Fe}}{I_{\text {nat }} \mathrm{Fe}} .
$$

From the measured SLD ( $\left.\mathrm{SLD}_{\text {meas }}\right){ }^{c}{ }^{57} \mathrm{Fe}_{3} \mathrm{O}_{4}$ at a given depth is calculated via Eq. (2), using the SLD of natural $\mathrm{Fe}_{3} \mathrm{O}_{4}$ $\left(\mathrm{SLD}_{\text {nat }} \mathrm{Fe}_{3} \mathrm{O}_{4}\right)$ and the SLD of ${ }^{57} \mathrm{Fe}_{3} \mathrm{O}_{4}\left(\mathrm{SLD}_{57} \mathrm{Fe}_{3} \mathrm{O}_{4}\right)$ :

$$
c_{57} \mathrm{Fe}_{3} \mathrm{O}_{4}=\frac{\mathrm{SLD}_{\text {meas }}-\mathrm{SLD}_{\text {nat }} \mathrm{Fe}_{3} \mathrm{O}_{4}}{\mathrm{SLD}_{57} \mathrm{Fe}_{3} \mathrm{O}_{4}-\mathrm{SLD}_{\text {nat }} \mathrm{Fe}_{3} \mathrm{O}_{4}} .
$$

As the SLD links scattering length and mass density, the parameters cannot be easily separated. A reduced sample density or surface roughness have the same effect on the SLD as a lower scattering length resulting from the sample's isotopic composition. This effect is negligible calculating $c_{57} \mathrm{Fe}_{3} \mathrm{O}_{4}$ by Eq. (2) as the determination of the tabulated scattering lengths of natural $\mathrm{Fe}$ and its isotopes is not fully consistent due to differing isotope compositions of the reference samples. Taking this into account, an error of at least $10 \%$ has to be considered for the calculation of the concentrations [38].

Nevertheless, the concentration profiles of sample A calculated from the SLD profiles after growth and after heating to $470 \mathrm{~K}$ and from the ToF-SIMS profile after annealing are in good agreement (see Fig. 7). Note that the fraction of isotopically labeled ${ }^{57} \mathrm{Fe}_{3} \mathrm{O}_{4}$ decreases upon further annealing, as seen by the decrease of the area underneath the SLD profiles. The concentrations obtained from both NR and ToF-SIMS consistently show the ${ }^{57} \mathrm{Fe}$ enrichment at the sample surface and the decay of $c_{57} \mathrm{Fe}$ at the film/substrate 

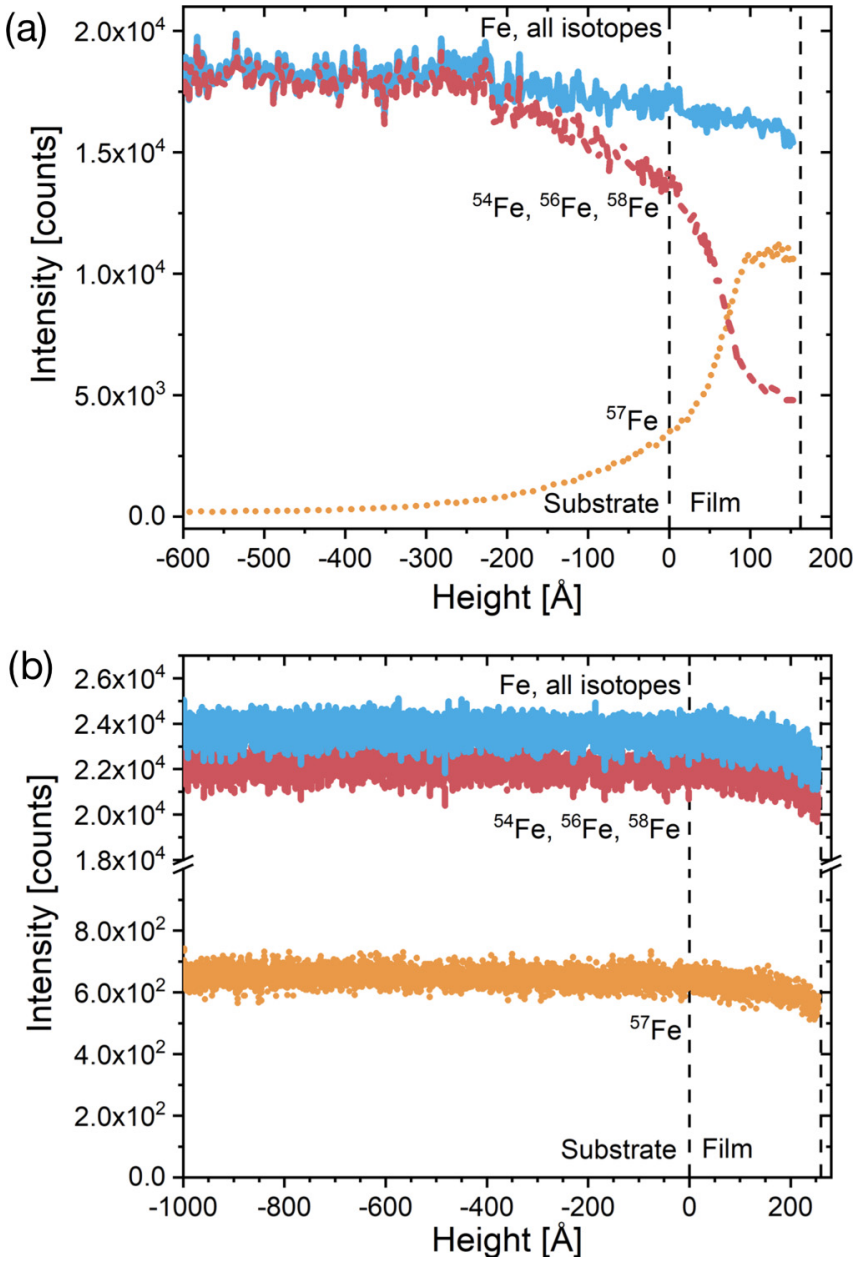

FIG. 6. ToF-SIMS profiling of (a) sample A after annealing to $470 \mathrm{~K}$ and (b) sample B after annealing to $770 \mathrm{~K}$. The depthdependent intensities of ${ }^{57} \mathrm{Fe}$ (orange dotted line), the other iron isotopes $\left({ }^{54} \mathrm{Fe},{ }^{56} \mathrm{Fe},{ }^{58} \mathrm{Fe}\right.$, red dashed line), and the total iron intensity of all isotopes (blue solid line) are shown. The interdiffusion zone is clearly recognizable for sample $\mathrm{A}$, whereas no ${ }^{57} \mathrm{Fe}$ gradient was observed for sample B.

interface. Comparing the profiles derived from NR before and after annealing to $470 \mathrm{~K}$, the decrease of $c^{57} \mathrm{Fe}$ throughout the film is clearly recognizable. For the film thickness and the shape of the concentration profile within the film the different methods yield nearly identical results. Differing from the $c^{57} \mathrm{Fe}_{3} \mathrm{O}_{4}$ profiles obtained from NR, a region of constant ${ }^{57} \mathrm{Fe}_{3} \mathrm{O}_{4}$ near the sample surface and an increased ${ }^{{ }_{57} \mathrm{Fe}_{3} \mathrm{O}_{4}}$ up to $200 \AA$ in the bulk are featured in the concentration profiles calculated from ToF-SIMS. As the sputtering process of the ToF-SIMS profiling not only removes material but also causes intermixing of isotopes in the ablation region, ${ }^{57} \mathrm{Fe}$ might have been dragged deeper into the sample during depth profiling. This might explain the region of constant ${ }^{{ }^{57} \mathrm{Fe}_{3} \mathrm{O}_{4}}$ at the sample surface and the increase of $c_{57} \mathrm{Fe}_{3} \mathrm{O}_{4}$ in the first few $\AA$ of the substrate compared to the profiles derived from NR. Furthermore, a low $c_{57} \mathrm{Fe}_{3} \mathrm{O}_{4}$ in the bulk cannot be resolved by NR as reflectivity in general can only resolve scattering length differences with an accuracy of a few percent. The tailing of ${ }^{{ }^{57} \mathrm{Fe}_{3} \mathrm{O}_{4}}$ into the substrate observed by ToF-SIMS

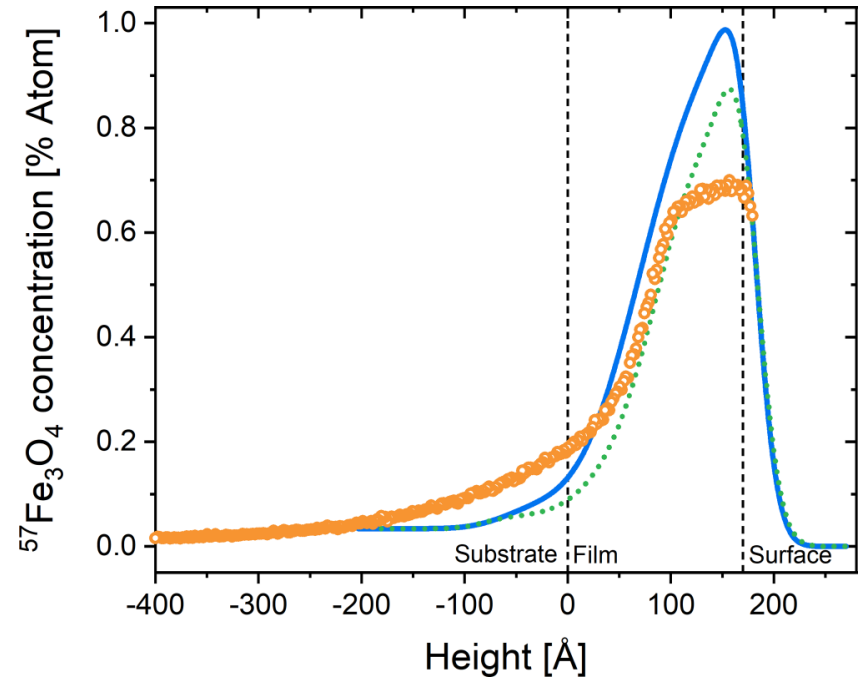

FIG. 7. Depth-dependent ${ }^{57} \mathrm{Fe}$ concentration profiles of sample A calculated from the SLD-profile before (blue solid line) and after UHV annealing to $470 \mathrm{~K}$ for $15 \mathrm{~min}$ (green dotted line) in comparison with the profile calculated from the ToF-SIMS intensity after annealing (orange open-dotted line).

therefore was not observable by NR. The smearing out of the ${ }^{57} \mathrm{Fe}$ profile in the first few $\AA$ obtained by NR compared to the profile obtained from ToF-SIMS is most likely related to surface roughness effects and the layer model applied for fitting the NR curves. As NR, unlike ToF-SIMS, probes an extended surface area, the concentration profiles derived from the SLD represent the average concentration profile of the whole sample. Local inhomogeneities that might result from the growth and temperature gradients during the annealing process causing inhomogeneous diffusion might also strongly influence the outcome of the ToF-SIMS profiling without being instantly recognizable.

\section{Estimation of diffusion coefficients}

The results of the NR measurements obtained after subsequent annealing steps, allow for estimating the diffusion lengths and coefficients. The relative change in the SLD profiles after each annealing step needs to be determined. Since the interface between the regions with and without ${ }^{57} \mathrm{Fe}$ is not abrupt, but rather smeared out and also not identical in shape, some representative average value needs to be determined. To this end, first a single exponential function was fitted to the SLD profiles from the different measurements (see Figs. S7 and S8 in the Supplemental Material). It was found that this function shape gives a rather accurate overall description of the SLD change from the bulk towards the surface. The choice for such a procedure and fit function was found to work with the obtained SLD profiles in the investigated temperature range and to be sufficient for the accuracy needed here. The following fit function, containing one single parameter $l$ for the characteristic interface width, was used:

$$
\mathrm{SLD}_{\text {meas }}=\mathrm{SLD}_{\mathrm{Fe}_{3} \mathrm{O}_{4}}-\Delta \mathrm{SLD} e^{\frac{x-x_{0}}{l}} \text {. }
$$

For sample $\mathrm{A}$, the position of the interface of film and substrate was set to $x_{0}=175 \AA$, for sample B, $x_{0}=248 \AA$. 
TABLE I. Diffusion coefficients and diffusion lengths determined from the characteristic width.

\begin{tabular}{|c|c|c|c|c|c|c|}
\hline Sample & Temperature (K) & Annealing time (s) & Pressure (mbar) & Characteristic width $(\AA)$ & $x_{d}(\AA)(\mathrm{fit})$ & $D\left(\mathrm{~m}^{2} / \mathrm{s}\right)$ \\
\hline A $175 \AA$ & 290 & - & - & 110 & - & - \\
\hline A $175 \AA$ & 470 & 900 & $1.8 \times 10^{-8}$ & 91 & $17 \pm 10$ & $3 \times 10^{-21}$ \\
\hline B $248 \AA$ & 290 & - & - & 130 & - & - \\
\hline B $248 \AA$ & 470 & 900 & $7.7 \times 10^{-8}$ & 91 & $36 \pm 10$ & $1 \times 10^{-20}$ \\
\hline B $248 \AA$ & 570 & 900 & $1.0 \times 10^{-7}$ & 56 & $35 \pm 7$ & $1 \times 10^{-20}$ \\
\hline B $248 \AA$ & 670 & 900 & $1.2 \times 10^{-7}$ & 9 & $46 \pm 3$ & $2 \times 10^{-20}$ \\
\hline
\end{tabular}

The measured SLD ( $\left.\mathrm{SLD}_{\text {meas }}\right)$, the SLD of the substrate $\left(\mathrm{SLD}_{\mathrm{Fe}_{3} \mathrm{O}_{4}}=0.69745 \mathrm{fm} / \AA^{3}\right)$ and the SLD difference of $\mathrm{Fe}_{3} \mathrm{O}_{4}$ and ${ }^{57} \mathrm{Fe}_{3} \mathrm{O}_{4}\left(\Delta \mathrm{SLD}=0.29045 \mathrm{fm} / \AA^{3}\right)$ are fixed parameters. The fitted curves are shown in Figs. S7 and S8 in the Supplemental Material [47]. Diffusion lengths for each temperature step shown in Table I were derived by subtracting the characteristic width at a given temperature step from the characteristic width of the previous temperature step. An experimental error of $\pm 5 \%$ resulting from the SLD sensitivity of NR and fitting errors was added to the characteristic widths. Temperature-dependent diffusion coefficients $D$ were calculated from the diffusion length $x_{d}$ and the annealing time $t$ via Eq. (4):

$$
D=\frac{x_{d}^{2}}{t} .
$$

Due to the diffusion at low temperatures, the intermixing was already completed after annealing to $670 \mathrm{~K}$. The diffusion distance determined for this heating step therefore has to be considered as a minimum value, as ions from the substrate already reached the sample surface. For the same reason, no diffusion length was calculated for annealing at $770 \mathrm{~K}$. The variation of the calculated diffusion lengths for samples $\mathrm{A}$ and $\mathrm{B}$ at $470 \mathrm{~K}$ gives an approximate order of the error bar. It might result from the higher initial intermixing of ${ }^{57} \mathrm{Fe}_{3} \mathrm{O}_{4}$ and $\mathrm{Fe}_{3} \mathrm{O}_{4}$ observed for sample A compared with sample $\mathrm{B}$ hampering the precise determination of the diffusion length.

As can be seen in Table I, the presented method introduces a relatively large error of the order of $50 \%$. Nevertheless, it is still instructive to discuss these results in view of earlier results by Dieckmann and Schmalzried (DS) [22-25]. The obtained diffusion constants of the order of $10^{-20} \mathrm{~m}^{2} / \mathrm{s}$ are found to be nearly constant in the investigated temperature range of 470-670 K. A direct comparison of the present values for $D$ with those expected from the model developed by DS is shown in Fig. 8(a).

Their model explicitly takes into account the equilibrium concentration of interstitials and vacancies, which determine the diffusion pathway and mechanism, as a function of oxygen partial pressure. In our experiment, the oxygen partial pressure during annealing is the parameter over which the least control was gained. During heating, the maximum pressure rose to around $10^{-7}$ mbar, which consists mostly of water. Still, this value can be used as an upper limit for the oxygen partial pressure to calculate the diffusion constants based on DS, which are shown in Fig. 8(a). The oxygen activity $a_{\mathrm{O}_{2}}$ is defined as $a_{\mathrm{O}_{2}}=p_{\mathrm{O}_{2}} / p_{\mathrm{O}_{2}}^{0}$ with $p_{\mathrm{O}_{2}}$ the partial oxygen pressure and $p_{\mathrm{O}_{2}}^{0}=1000$ mbar. Clearly the expected values are about 4-5 orders of magnitude higher than our experimental ones.
This discrepancy does not change in the investigated temperature range when using a more realistic oxygen partial pressure of $10^{-12}$ mbar. For the extremely low oxygen partial pressure of $10^{-25}$ mbar does the DS model predict diffusion constants of the order of $10^{-20} \mathrm{~m}^{2} / \mathrm{s}$, as experimentally observed. Although we cannot rule out completely that the oxygen partial pressure reached such low values in our UHV system, it does seem unlikely. Figure 8(b) also shows the diffusion constant as a function of $a_{\mathrm{O}_{2}}$ for a constant temperature of $570 \mathrm{~K}$, showing the particular $\mathrm{V}$ shape, with its minimum around $a_{\mathrm{O}_{2}}=10^{-38}$. The curve shows that the model predicts extremely low diffusion coefficients for decreasing oxygen partial pressures. The sign change of the slope of the partial derivatives $\partial D / \partial a_{\mathrm{O}_{2}}$ and $\partial D / \partial(1 / T)$ marks ranges where either the vacancy or interstitial diffusion mechanism prevails. The experimental data show a slope of $-0.06 \pm 0.04 \mathrm{eV}$, with respect to the inverse temperature, of which the sign seems significant. The sign of this slope corresponds with the DS model calculated for oxygen partial pressures of $10^{-7}$ and $10^{-12}$, but not for $10^{-25}$ mbar. At this particular pressure, the interplay between
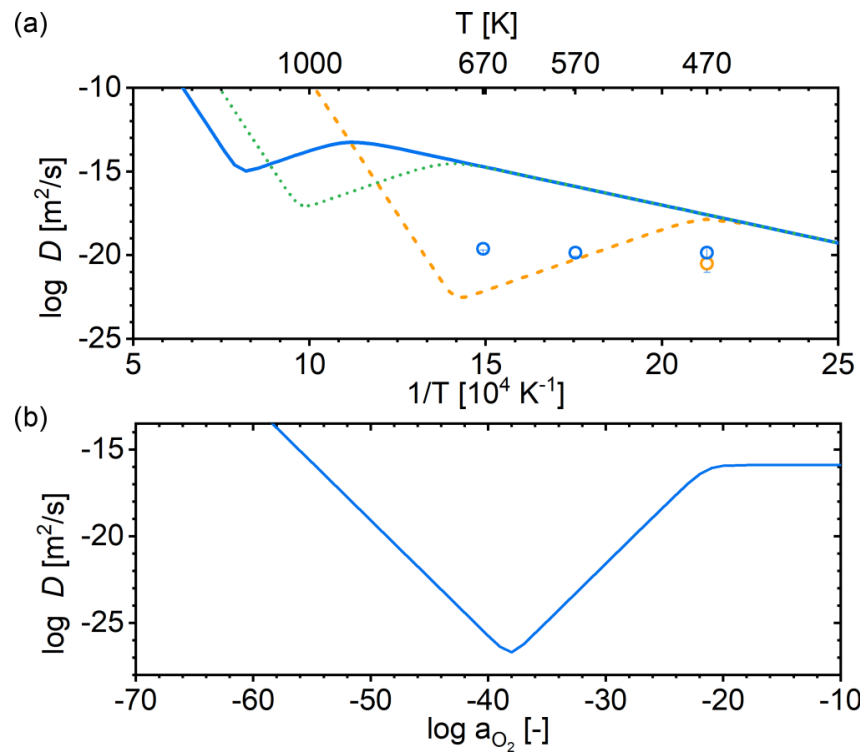

FIG. 8. (a) Experimental values of the diffusion constants $D$ of sample A (orange circle) and sample B (blue circles) vs inverse temperature as listed in Table I plotted with the values of $D$ based on the model by Schmalzried and Dieckmann, as explained in the main text, for oxygen partial pressures of $10^{-7}$ mbar (blue solid line), $10^{-12} \mathrm{mbar}$ (green dotted line), and $10^{-25} \mathrm{mbar}$ (orange dashed line). (b) Diffusion coefficient $D$ vs the oxygen activity $\left(a_{\mathrm{O}_{2}}\right)$ at a constant temperature of $570 \mathrm{~K}$, according to Schmalzried and Dieckmann. 
the equilibrium vacancy and interstitial concentrations leads to an increase in $D$ upon lowering the temperature in the range of $470-670 \mathrm{~K}$. This thus marks a special region in the $\left(T, a_{\mathrm{O}_{2}}\right)$ space and shows that the diffusion critically depends on the available defects and correlations between the two different mechanisms [25]. This leads to the following possible explanation for the observed low diffusion constants. The UHV-grown thin films are not yet in equilibrium with respect to the concentration of vacancies and interstitials, once the annealing steps begin. Rather, the defect concentrations are much lower than given by thermodynamic equilibrium. Since the diffusion depends on the availability of defect sites, these out-of-equilibrium samples show much lower diffusion than expected. One way for the system to create and reach the equilibrium defect concentrations is by expulsion of Fe ions, which reoxidize at the surface $[14,20]$. The rate at which this can occur depends on the intrinsic diffusion, which is already low, and on the availability of oxygen. Since oxygen also needs to dissociate before reoxidizing the iron, there will be a kinetic barrier for this process, which may lower the overall mobility of iron ions in the lattice even more.

\section{CONCLUSION}

Exploiting the neutron scattering length difference of ${ }^{57} \mathrm{Fe}_{3} \mathrm{O}_{4}$ thin films and natural $\mathrm{Fe}_{3} \mathrm{O}_{4}$ substrates we observed the near-surface cation diffusion in magnetite in a temperature range between 470 and $770 \mathrm{~K}$ by a combined neutron reflectivity and ToF-SIMS study. The ${ }^{57} \mathrm{Fe}_{3} \mathrm{O}_{4}$ thin films were homoepitaxially grown on natural (001)-polished $\mathrm{Fe}_{3} \mathrm{O}_{4}$ substrates to label the near-surface cations. The formation of a $(\sqrt{2} \times \sqrt{2}) \mathrm{R} 45^{\circ}$ reconstructed surface observed by LEED after the growth procedure indicated that the ${ }^{57} \mathrm{Fe}_{3} \mathrm{O}_{4}$ thin films consisted of nearly stoichiometric $\mathrm{Fe}_{3} \mathrm{O}_{4}$. Precharacterization by ex situ XRR revealed a slightly reduced density of the thin films compared to bulk $\mathrm{Fe}_{3} \mathrm{O}_{4}$ which might result from an incomplete coverage of the substrate and/or cation deficient structure due to overoxidation during the growth process.

Neutron reflectivity showed that interdiffusion of ${ }^{57} \mathrm{Fe}_{3} \mathrm{O}_{4}$ and $\mathrm{Fe}_{3} \mathrm{O}_{4}$ already took place during sample preparation at $420 \mathrm{~K}$ in $4 \times 10^{-6}$ mbar $_{2}$. By stepwise annealing of the thin films in UHV and subsequent NR, cation transport was observed in the temperature range from 470 to $770 \mathrm{~K}$. The cation exchange between film and substrate was completed after annealing to $670 \mathrm{~K}$. The findings from NR were confirmed by ToF-SIMS showing a good agreement of the ${ }^{57} \mathrm{Fe}$ distribution profiles calculated from NR and measured by ToF-SIMS. Our results show that down to the relatively low temperature of at least $470 \mathrm{~K}$ cation transport over several nanometers in the near-surface region of magnetite occurs. Most likely, this process also takes place at even lower temperatures, as concluded from the measurements of the as-prepared samples at $420 \mathrm{~K}$.

The diffusion lengths found in our study of around 2 to $5 \mathrm{~nm}$ at 470 to $670 \mathrm{~K}\left(D \simeq 10^{-20} \mathrm{~m} / \mathrm{s}^{2}\right)$ are considerably smaller than diffusion lengths of up to $1 \mu \mathrm{m}(D \simeq$ $10^{-16} \mathrm{~m} / \mathrm{s}^{2}$ ) expected using the model by Dieckmann and Schmalzried [22,25] extrapolated to lower temperatures and assuming oxygen partial pressures of $10^{-12}$ mbar or higher. Only by assuming a very low and unlikely oxygen partial pressure, of the order of $10^{-25}$ mbar, does the aforementioned model predict as low diffusion constants as experimentally observed. The large differences between the well-established model for bulk diffusion and the present results, when assuming that the oxygen partial pressure was not extremely low in the experiments, may be an indication of very low out-ofequilibrium defect concentrations in the grown films. In such a scenario, the overall observed iron mobility is determined by the intrinsic diffusion and by the rate at which point defects form. The system may reach the equilibrium concentration of point defects by changing the stoichiometry in the selvedge and by forming new oxide material at the surface. As more defects (vacancies and/or interstitials) are formed within the selvedge, the diffusion will also increase. A rate limiting step for this process will be the dissociation of oxygen, which is needed to reoxidize the iron ions.

Diffusion over several nanometers down to $470 \mathrm{~K}$ has been observed to take place in time spans of the order of $15 \mathrm{~min}$. These results show that near-surface cation diffusion needs to be considered when discussing processes like catalytic reactions and adsorption under different oxygen chemical potentials at these temperatures.

\section{ACKNOWLEDGMENTS}

This work is based upon experiments performed at the MARIA instrument and utilizing the MBE setup, both operated by JCNS at the Heinz Maier-Leibnitz Zentrum (MLZ), Garching, Germany. It was funded by the Deutsche Forschungsgemeinschaft (DFG, German Research Foundation) Project No. 192346071 SFB 986.
[1] G. S. Parkinson, Surf. Sci. Rep. 71, 272 (2016).

[2] S. A. Chambers and S. A. Joyce, Surf. Sci. 420, 111 (1999).

[3] M. Louis Néel, Ann. Phys. 12, 137 (1948).

[4] L. Huang, B. Han, Q. Zhang, M. Fan, and H. Cheng, J. Phys. Chem. C 119, 28934 (2015).

[5] J. B. Butt, Catal. Lett. 7, 61 (1990).

[6] W. Eerenstein, T. T. M. Palstra, S. S. Saxena, and T. Hibma, Phys. Rev. Lett. 88, 247204 (2002).

[7] A. V. Ramos, J.-B. Moussy, M.-J. Guittet, A. M. Bataille, M. Gautier-Soyer, M. Viret, C. Gatel, P. Bayle-Guillemaud, and E. Snoeck, J. Appl. Phys. 100, 103902 (2006).
[8] J. Zhang, W. Liu, M. Zhang, X. Zhang, W. Niu, M. Gao, X. Wang, J. Du, R. Zhang, and Y. Xu, J. Magn. Magn. Mater. 432, 472 (2017).

[9] A. Dreyer, A. Feld, A. Kornowski, E. D. Yilmaz, H. Noei, A. Meyer, T. Krekeler, C. Jiao, A. Stierle, V. Abetz, H. Weller, and G. A. Schneider, Nat. Mater. 15, 522 (2016).

[10] G. Mirabello, A. Keizer, P. H. H. Bomans, A. Kovács, R. E. Dunin-Borkowski, N. A. J. M. Sommerdijk, and H. Friedrich, Chem. Mater. 31, 7320 (2019).

[11] C. Ratnasamy and J. P. Wagner, Catal. Rev. 51, 325 (2009). 
[12] R. Bliem, E. McDermott, P. Ferstl, M. Setvin, O. Gamba, J. Pavelec, M. A. Schneider, M. Schmid, U. Diebold, P. Blaha, L. Hammer, and G. S. Parkinson, Science 346, 1215 (2014).

[13] B. Arndt, R. Bliem, O. Gamba, J. E. van der Hoeven, H. Noei, U. Diebold, G. S. Parkinson, and A. Stierle, Surf. Sci. 653, 76 (2016).

[14] S. Nie, E. Starodub, M. Monti, D. A. Siegel, L. Vergara, F. El Gabaly, N. C. Bartelt, J. de la Figuera, and K. F. McCarty, J. Am. Chem. Soc. 135, 10091 (2013).

[15] D. Ihle and B. Lorenz, J. Phys. C: Solid State Phys. 19, 5239 (1986).

[16] G. Ketteler, W. Weiss, W. Ranke, and R. Schlögl, Phys. Chem. Chem. Phys. 3, 1114 (2001).

[17] G. S. Parkinson, N. Mulakaluri, Y. Losovyj, P. Jacobson, R. Pentcheva, and U. Diebold, Phys. Rev. B 82, 125413 (2010).

[18] B. Arndt, K. Sellschopp, M. Creutzburg, E. Grånäs, K. Krausert, V. Vonk, S. Müller, H. Noei, G. B. V. Feldbauer, and A. Stierle, Commun. Chem. 2, 92 (2019).

[19] B. Arndt, M. Creutzburg, E. Grånäs, S. Volkov, K. Krausert, A. Vlad, H. Noei, and A. Stierle, J. Phys. Chem. C 123, 26662 (2019).

[20] B. Arndt, B. A. J. Lechner, A. Bourgund, E. Grånäs, M. Creutzburg, K. Krausert, J. Hulva, G. S. Parkinson, M. Schmid, V. Vonk, F. Esch, and A. Stierle, Phys. Chem. Chem. Phys. 22, 8336 (2020).

[21] A. Atkinson, M. L. O’Dwyer, and R. I. Taylor, J. Mater. Sci. 18, 2371 (1983).

[22] R. Dieckmann and H. Schmalzried, Ber. Bunsenges. Phys. Chem. 81, 344 (1977).

[23] R. Dieckmann and H. Schmalzried, Ber. Bunsenges. Phys. Chem. 81, 414 (1977).

[24] R. Dieckmann, T. O. Mason, J. D. Hodge, and H. Schmalzried, Ber. Bunsenges. Phys. Chem. 82, 778 (1978).

[25] R. Dieckmann and H. Schmalzried, Ber. Bunsenges. Phys. Chem. 90, 564 (1986).

[26] N. L. Peterson, W. K. Chen, and D. Wolf, J. Phys. Chem. Solids 41, 709 (1980).

[27] K. D. Becker, V. v. Wurmb, and F. J. Litterst, J. Phys. Chem. Solids 54, 923 (1993).

[28] S. Hallström, L. Höglund, and J. Ågren, Acta Mater. 59, 53 (2011).

[29] J. A. Van Orman and K. L. Crispin, Rev. Mineral. Geochem. 72, 757 (2010).

[30] R. J. D. Tilley, Defects in Solids (John Wiley and Sons, New York, 2008).

[31] R. Dieckmann, Ber. Bunsenges. Phys. Chem. 86, 112 (1982).
[32] R. Dieckmann, M. R. Hilton, and T. O. Mason, Ber. Bunsenges. Phys. Chem. 91, 59 (1987).

[33] C. L. Muhich, V. J. Aston, R. M. Trottier, A. W. Weimer, and C. B. Musgrave, Chem. Mater. 28, 214 (2016).

[34] H. Schmidt, M. Gupta, and M. Bruns, Phys. Rev. Lett. 96, 055901 (2006)

[35] H. Schmidt, M. Gupta, T. Gutberlet, J. Stahn, and M. Bruns, Acta Mater. 56, 464 (2008).

[36] H. Schmidt, E. Hüger, S. Chakravarty, J. Stahn, T. Gutberlet, U. Tietze, and D. Lott, Adv. Eng. Mater. 11, 446 (2009).

[37] S. Chakravarty, H. Schmidt, U. Tietze, D. Lott, N. P. Lalla, and A. Gupta, Phys. Rev. B 80, 014111 (2009).

[38] A.-J. Dianoux and G. Lander, Eds., Neutron Data Booklet (Institut Laue-Langevin, Grenoble, France, 2003).

[39] A. Stierle, T. F. Keller, H. Noei, V. Vonk, and R. Roehlsberger, JLSRF 2, A76 (2016).

[40] S. Mattauch, A. Koutsioubas, and S. Pütter, JLSRF 1, A8 (2015).

[41] S. Mattauch, A. Koutsioubas, U. Rücker, D. Korolkov, V. Fracassi, J. Daemen, R. Schmitz, K. Bussmann, F. Suxdorf, M. Wagener, P. Kämmerling, H. Kleines, L. Fleischhauer-Fuß, M. Bednareck, V. Ossoviy, A. Nebel, P. Stronciwilk, S. Staringer, M. Gödel, A. Richter, H. Kusche, T. Kohnke, A. Ioffe, E. Babcock, Z. Salhi, and T. Bruckel, J. Appl. Crystallogr. 51, 646 (2018).

[42] T. Fujii, M. Takano, R. Katano, Y. Bando, and Y. Isozumi, J. Cryst. Growth 99, 606 (1990)

[43] J. M. Gaines, P. J. H. Bloemen, J. T. Kohlhepp, C. W. T. BulleLieuwma, R. M. Wolf, A. Reinders, R. M. Jungblut, P. A. A. van der Heijden, J. T. W. M. van Eemeren, J. a. de Stegge, and W. J. M. de Jonge, Surf. Sci. 373, 85 (1997).

[44] F. Bertram, C. Deiter, O. Hoefert, T. Schemme, F. Timmer, M. Suendorf, B. Zimmermann, and J. Wollschläger, J. Phys. D: Appl. Phys. 45, 395302 (2012).

[45] B. Handke, J. Haber, T. Ślęzak, M. Kubik, and J. Korecki, Vacuum 63, 331 (2001).

[46] A. Stierle, T. Mühge, and H. Zabel, J. Mater. Res. 9, 884 (1994).

[47] See Supplemental Material at http://link.aps.org/supplemental/ 10.1103/PhysRevResearch.2.023406 for more details on the sample characterization, fitting parameters for XRR and NR, simulations of NR curves for ideal sample geometries, and additional details of the determination of the diffusion lengths.

[48] T. Schemme, A. Krampf, F. Bertram, T. Kuschel, K. Kuepper, and J. Wollschläger, J. Appl. Phys. 118, 113904 (2015).

[49] L. G. Parratt, Phys. Rev. 95, 359 (1954).

[50] M. Björck and G. Andersson, J. Appl. Crystallogr. 40, 1174 (2007). 